added separately, can reassemble to form active catalysts". But proving that spliceosomal snRNAs have a catalytic role remains a major experimental challenge.

\section{Intron mobility and evolution}

The discovery of splicing immediately prompted the question of how introns originated. The two extreme (but not necessarily exclusive) solutions as reviewed by P. Sharp (Massachusetts Institute of Technology) are either that introns were present in ancestral genes, or that introns were inserted into genes that were originally continuous. Although a decisive answer has not yet been reached, the feasibility of intron insertion has now been clearly established in several diverse systems.

One potential insertion mechanism, completely RNA driven, is that of reverse splicing in which an excised intron, which contains all of the catalytic activity, inserts back into an unrelated RNA. Reverse splicing would enable the same intron to be placed into different RNAs. The feasibility of this mechanism has been illustrated in vitro for a group I intron (Cech). (Of course, a DNA copy of the newly assembled RNA would have to be generated and incorporated into the genome.)

A second class of insertion mechanisms, which, in contrast to reverse splicing, is DNA-based, involves intron-encoded proteins. Introns are known to encode an assortment of products including ribosomal proteins, splicing maturases and endonucleases. One of the best-understood systems is the intron-containing $21 \mathrm{~S}$ ribosomal RNA gene of the yeast Saccharomyces cerevisiae ${ }^{10}$. This intron encodes an endonuclease that cleaves at a specific site in the genes of intron-lacking (omega $^{-}$) variants. The resulting doublestranded break promotes efficient conversion to intron-containing (omega ${ }^{+}$) forms (B. Dujon, Pasteur Institute). Analogous intron transfer by gene conversion was found in several other cases, including a Physarum RNA intron (P. Vogt, Cornell University); a Chlamydomonas chloroplast rRNA intron (C. Lemieux, Université Laval); and an $S$. cerevisiae mitochondrial structural (coxI) gene (Perlman). Thus gene conversion seems to be a common mechanism for transfer of group I introns in eukaryotes.

A comparable intron-transfer mechanism has also been discovered in a prokaryote, the bacteriophage T4. There are group I introns in three $\mathrm{T} 4$ genes $(t d$, $n r d \mathrm{~B}$ and $\operatorname{sun} \mathrm{Y})^{11,12}$. Are these prokaryotic introns relics or recent acquisitions? The sporadic presence of introns among different T4 strains is more consistent with the latter possibility, which is supported by the demonstration that two T4 introns can be efficiently transferred from introncontaining to intron-lacking $\mathrm{T}$-even phases (M. Belfort, New York State Department of Health). In each case, transfer is dependent on an open reading frame in the intron. Insertion is at a specific site within the cognate gene of the intron-less strain and requires flanking exon homology? There is no obvious selective advantage for the presence of introns, and thus the intron could be an example of a neutral molecular parasite. In any case, these studies show that introns are capable of invading the genomes of modern organisms, and are therefore not necessarily vestigial elements from the past.

Are introns in $\mathrm{T} 4$ a prokaryotic anomaly? Apparently not, for D. Shub (State University of New York, Albany) has also found a group I intron in the DNA polymerase gene of SP01, a Bacillus subtilis bacteriophage. The discovery of introns in another prokaryote emphasizes the existence of group I introns in organisms that are otherwise highly genetically dissimilar. Given Belfort's demonstration of intron transfer between related $\mathrm{T}$-even phages, the possibility that group I introns have been disseminated by inter-species transfer becomes irresistible speculation.

An example of what seems to be an intron that has escaped into semiindependence has also been described. Mitochondria of the fungus Neurospora crassa harbour double-stranded DNA plasmids, whose nucleotide sequence and genetic organization suggest that they evolved from mitochondrial group I introns ${ }^{13}$. A. Lambowitz (Ohio State University) presented biochemical evidence for a mitochondrial reverse-transcriptase activity, which is encoded by the plasmid itself. The reverse transcriptase synthesizes complete $(-)$ strands using the fulllength $(+)$ strand primary transcript of the plasmid as a template. These results imply a replication scheme in which the intronderived plasmid propagates itself via an RNA intermediate that is copied by the reverse transcriptase back into doublestranded DNA. Several features of this process suggest that it may be a primitive type of reverse transcription, ancestral to the retroviral mechanism. These results raise the possibility that group I-related $N$. crassa mitochondrial plasmids might be a missing link in the evolutionary chain that led to retroviruses.
James. B.D. Olsen G.J. Liu, JL \& Pace N. R. Cell 52 $19(1988)$
2. Riesner. D. \& Gross, H.J. A. Rev, Biochem. 54. 531 (1985)
Forster. A.C. \& Symons. R.H. Cell 49, 211 (1987)
. Uhlenbeck. O.C. Nuture 328, 596 (1987).
Sharmeen Let al J. Virot. 62.2674 (1988)
Cech. T.R. \& Bass. B.L. A. Re1: Biochem. 55. 599 (1986)
Pudgett. R A elal A Re: Biochem. 55. 1119 (1986).
Green. M.R. A. Rev. Genet. 20.671 (1986)
Green. M.R. A. Re'. Genet. 20. 671 (1986).
Jarrell. K. A. et al. Molec cell. Biol. 8. 2361 (1988)
10. Colleaux. Let al. Proc, nam. Acad. Sci. U.S.A. 85. 6122 (1988).
11. Chu. F.K. et al. Proc natn. Acad. Sci. U.S.A. 81, 3049 (1984)
2. Shub. D.A. et al. Proc. natm. Acad. Sci. U.S.A. 85. 1151 (1988).
13. Nargang. F.E.et al. Cell 38, $441(19 \times 4)$

Michael R. Green is in the Department of Bio chemistry and Molecular Biology, Harvard University, Cambridge, Massachusetts 02138, USA.

\section{Daedalus}

\section{Winter's icy grip}

While dicing with death on an icy motorway recently, Daedalus began to muse on the small amount of water necessary to destroy the adhesion of a tyre on the road. For it is, of course, the tiny film of melt-water between the ice and the tyre which does the damage: solid ice itself would give an excellent grip.

The current answer is simply to melt all the ice, by covering the whole road with a liberal dressing of corrosive salt. But Daedalus recalls the ingenious technology used on the old steam locomotives. When their wheels threatened to slip on the rails, a steam-injector sprayed sand into the exact point of contact between wheel and rail, and restored the grip. So DREADCO's chemists are bringing this idea up to date. They are experimenting with the polyacrylate 'super-slurper' compounds which soak up urine in babies' nappies. A good waterabsorbing polymer can take up dozens of times its own weight of water, and still remain dry to the touch. Sprayed continuously onto a tyre, even a very light dusting of such a water absorber should take up the few micrometres of water film which do all the damage. It will be converted into a dry or slightly tacky film with excellent tractive adhesion to the solid ice beneath.

Daedalus calculates that a mere ten grams per kilometre of his 'Tyre Talcum' will keep a car utterly steady on the most treacherous ice. And as each passing vehicle adds its tiny contribution, the ice itself will slowly acquire such a loading of Tyre Talcum that it will cease to be slippery anyway: any melt-water will be absorbed as fast as it forms. Even when the ice begins to thaw, the resulting slush will be thick and doughy, with a firm, sticky grip on the passing tyres.

Thus the menace of the icy road will be overcome. The vast global investment in snow ploughs, gritting lorries, salt depots, tyre chains and so forth will be redundant; wheeled traffic will run reliably in all weathers. Pedestrians, however, will still be at risk. For their benefit Daedalus is devising a Tyre-Talcum-dispensing boot. At each step, the compression of a small air bulb sprays a light dusting of Tyre Talcum into the footprint area. Farmers, rural postmen and tottery pensioners, not to mention arctic explorers and mountaineers, should all welcome it.

But like every technological development, Tyre Talcum has its potential for social damage. Nations like Britain, whose winter is too unreliable to give its wintersports teams the practice they need, may welcome the chance to dust it in secret and undetectable patches on ski slopes, sleigh runs, or ice hockey rinks, to sabotage their more accomplished rivals. David Jones 